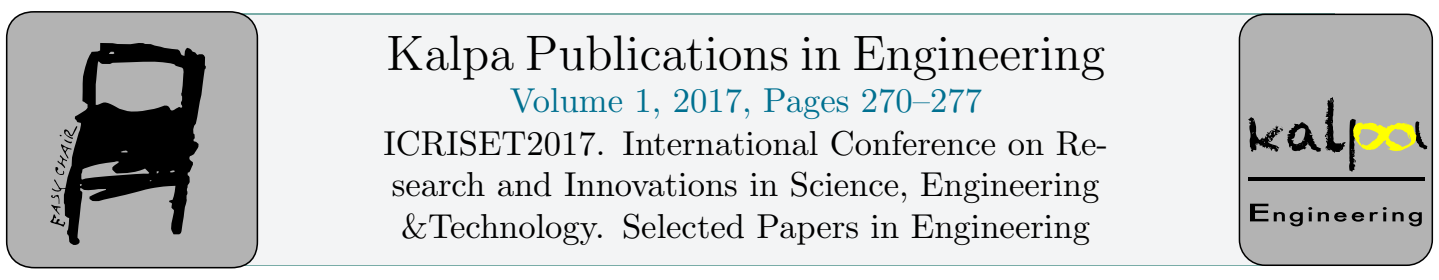

\title{
Active Power Control of PV System in MPPT and CPG Mode
}

\author{
Maheshwariba P. Zala ${ }^{1}$, Prof.Mahesh H. Pandya ${ }^{2}$, Khoda N. Odedra ${ }^{3}$, \\ Dhaval P. Patel ${ }^{4}$ \\ ${ }_{1,2,3,4}$ Lakhdhirji Engineering College, Morbi \\ ${ }^{1}$ zalamaheshwariba@gmail.com, 2pandyamh@rediffmail.com, \\ ${ }^{3}$ odedrakhodal11@gmail.com, ${ }^{4}$ dhaval211093@gmail.com
}

\begin{abstract}
Integration of the renewable source in the existing distribution network under varying load profile is a daunting task. This paper presents the active power control of the PV system. This PV renewable source availability and load demand in the distribution network are mismatching. The extraction of maximum PV power is enhanced with Perturb \& Observe algorithm. In this paper the Maximum Power Point Tracking (MPPT) algorithm is coordinated with Constant Power Generation (CPG) control to address the high PV penetration issue. The control algorithm is implemented in MATLAB Simulink environment. The efficacy of proposed technique is tested for variation in temperature, and irradiation level. The simulation results are justified the active power control in dual mode of operation MPPT and CPG to mitigate high PV penetration issue.
\end{abstract}

Keywords-MPPT;CPG;Active Power Control; P\&O algorithm

\section{Introduction}

Today, Non-Conventional Energy Resources (e.g. solar energy, wind energy) are growing very rapidly due to the need of Pollution Free and reliable electricity generation. It also reduces the Transmission and Distribution losses. So, its share increases in electricity generation rapidly. PV output power depends on Environmental Condition like Solar Irradiation level and Ambient Temperature. So, its Output Power is fluctuating one [1]-[2]. Due to still increasing installation of PV System, aging Transmission and Distribution line overloaded [3]-[4].

For instance, BCC reported that high PV penetration, Overloaded the parts of Northern Ireland's grid in High Solar Irradiation Day [5]. So to further cope with high PV installation, the Distributed System Operators are forced to expand Transmission and Distribution line or Battery Storage Requirement. However, these both impose extra cost on the system and also the life of battery is limited. Otherwise reduce the PV installation. However, these options are not viable. Imaginary Power Control or True Power Control also alleviate the voltage rise on Distributed Feeder. However, True Power 
reduction shows more powerfulness than Imaginary Power control due to low X/R ratio of Distribution feeder [6]. So, Constant Power Generation (CPG) control is proposed to limit the Maximum feed in power to certain level [7]-[9].

Constant Power Generation can be achieved by using three different techniques: 1) By controlling power (P-CPG), 2) By controlling current (I-CPG), and 3) By controlling voltage (P\&O-CPG). However, $\mathrm{P} \& \mathrm{O}-\mathrm{CPG}$ or voltage control is effective in terms of powerfulness when PV System operate in left side of MPP. However, when system transit from MPPT to CPG mode and CPG to MPPT mode there is large Overshoot and Power loss occur. So, to minimize this Overshoot and Power loss adaptive step size is selected according to the fast increase or decrease in detected Irradiation level [10].

\section{Maximum Power Point Tracking}

This MPPT algorithm is depends on Maximum Power Transfer theorem which says that "Maximum Power is transferred to the load when load impedance matches the input impedance of the system".

\subsection{PV Panel Characteristic}

Solar cell converts solar energy directly into electricity. Its operation is based on Photovoltaic effect of solar cell. PV panel output power rely on Environmental condition. As the Solar Irradiation increases and Ambient Temperature decreases, the PV panel output power increases as shown in fig 1 and 2 respectively. So, to maximize the efficiency of PV system, PV Panel should operate at such a point (i.e. Combination of voltage and current) where PV panel give maximum power output. This working point of PV Panel is known as Maximum Power Point (MPP) as shown in fig 3.

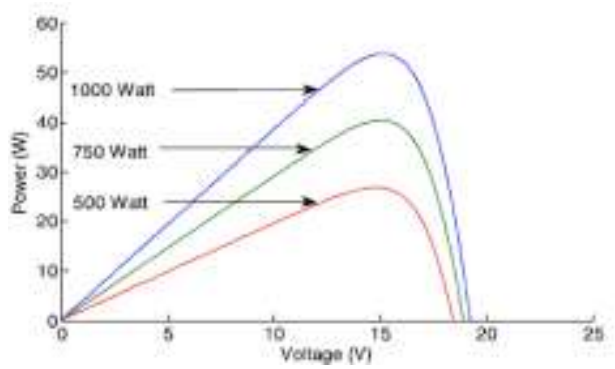

Figure 1: Effect of change in Solar Insolation on P-V Curve

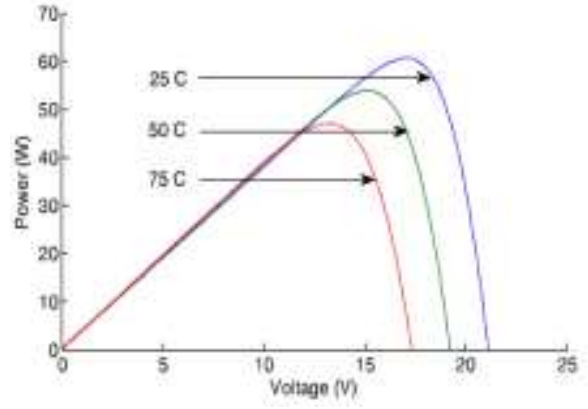

Figure 2: Effect of change in Temperature on $\mathrm{P}-\mathrm{V}$ curve

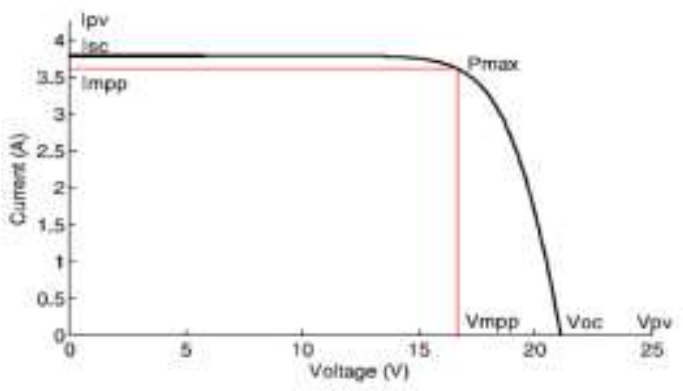

Figure 3: I-V Curve of PV Module 


\subsection{Boost Converter}

DC-DC converter is the main component to achieve MPPT/CPG control. It is used to equalize the load side impedance to the input impedance of PV Panel by altering the duty cycle of Step-up converter. So that maximal power is available at the load. The ratio of output voltage to input voltage is given by:

$$
\frac{V_{0}}{V_{\text {in }}}=\frac{1}{1-D}
$$

\section{Constant Power Generation Control}

Constant Power Generation control is implemented by altering the MPPT algorithm. The MPPTCPG control is realized by regulating the duty cycle of DC-DC converter (i.e. Boost converter). PV system operates in two mode based on the PV output power and set maximum feed in power limit $\mathrm{P}_{\text {limit }}$ - either in Maximum Power Point Tracking (MPPT) mode or Constant Power Generation (CPG) mode.

When grid capacity $\mathrm{P}_{\text {limit }}$ is more than the PV output power $\mathrm{P}_{\mathrm{pv}}$, then the PV System operates in MPPT mode to track maximum power point and when the grid capacity $\mathrm{P}_{\text {limit }}$ is smaller than the PV output power $\mathrm{P}_{\mathrm{pv}}$, then the PV System operates into Constant Power Generation (CPG) to restrict the maximal feed in power to $\mathrm{P}_{\text {limit. }}$

$$
P_{p v}= \begin{cases}P_{M P P T}, & \text { when } \mathrm{P}_{p v} \leq P_{\text {limit }} \\ P_{\lim i t}, & \text { when } \mathrm{P}_{p v}>P_{\lim i t}\end{cases}
$$

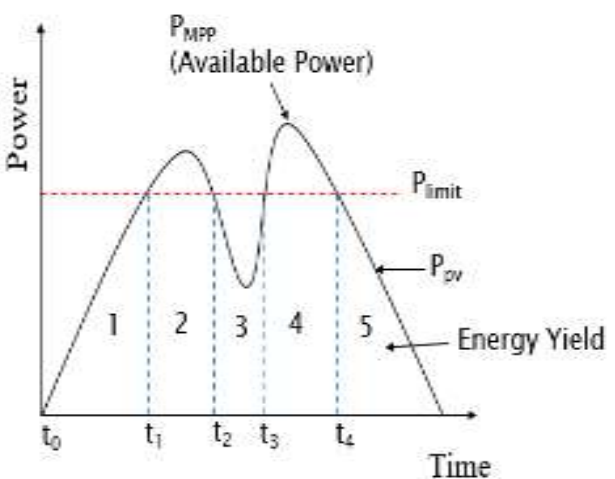

Figure 4: Operating region of PV System during Day

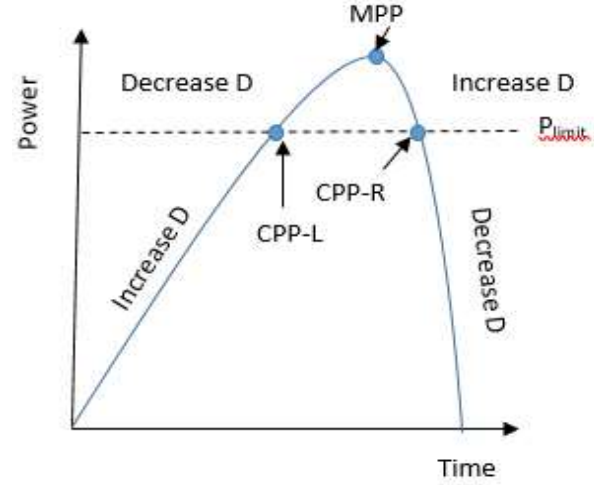

Figure 5: MPPT with CPG mode to limit maximum feed in power to $P_{\text {limit }}$

Fig 4. Shows Operating region of PV system During day. PV System operate in MPPT mode during operating region 1,3,5 and in CPG mode during operating region 2,4.

PV System can operate in Constant Power Generation Control in either side of MPP i.e. either on left hand side of MPP (CPP-L) or right side of MPP (CPP-R). If Single stage PV System is used, then CPG operation is restricted to the Right hand side of MPP (CPP-R). So, when fast decrease in irradiation condition is experienced, operating point goes to very high impedance condition and it decreases the robustness of the system. So, to cope with this problem, Double stage PV System is used which expand the operating region of PV System to the left hand side of MPP (CPP-L) also. So the PV System regulate its power at left hand side of MPP and stable operation is always achieved (Fig 5). 


\section{Algorithm of MPPT and CPG}

\subsection{P\&O- based MPPT-CPG algorithm}

$\mathrm{P} \& \mathrm{O}$ method changes the operating voltage of PV cell in either direction and then compares the present value of PV output power with $\mathrm{P}_{\text {limit. }}$ If present value of PV power is less than the $\mathrm{P}_{\text {limit }}$, then compare the present value of PV power with the previous value of PV power. if this difference is greater than zero then algorithm perturb in the same direction, otherwise it moves into opposite direction. If present value of PV power is more than $\mathrm{P}_{\text {limit, }}$, then compare the present value of PV power with the previous value of PV power. if this difference is greater than zero, then algorithm perturb in opposite direction otherwise it moves in same direction (Fig.5). Flow Chart of Perturb and Observe (P\&O)- based MPPT-CPG Algorithm is shown in Fig.6

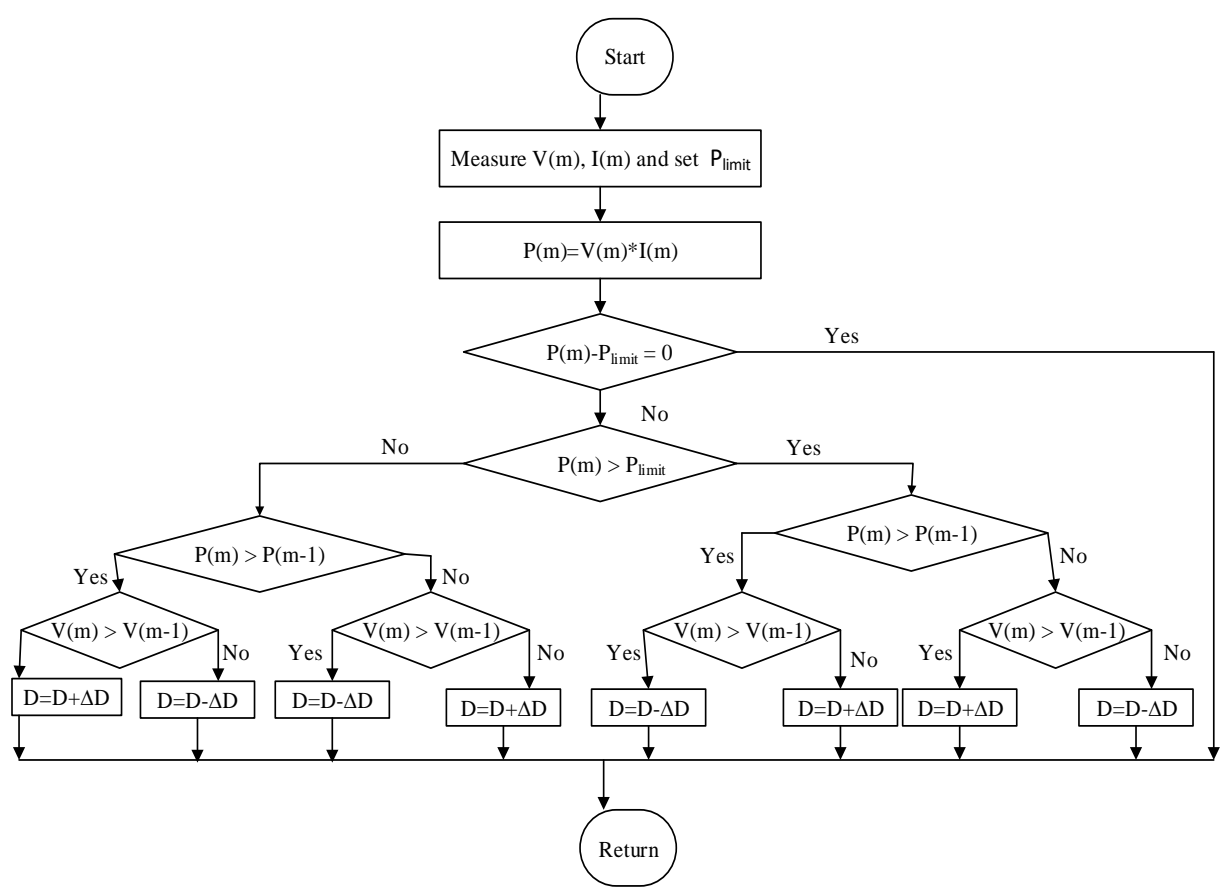

Figure 6: Flow Chart of P\&O- based MPPT-CPG Algorithm

\section{Simulation Result}

\subsection{System Parameter}

\begin{tabular}{|l|c|c|c|}
\hline \multicolumn{1}{|c|}{ Parameters } & Symbol & Value & Unit \\
\hline Maximum Power of PV module & $\mathrm{P}_{\mathrm{MPP}}$ & 213.15 & $\mathrm{~W}$ \\
\hline Voltage at MPP & $\mathrm{V}_{\mathrm{MPP}}$ & 29 & Volt \\
\hline Voltage at Open Circuit & $\mathrm{V}_{\mathrm{oc}}$ & 36.3 & Volt \\
\hline Current at MPP & $\mathrm{I}_{\mathrm{MPP}}$ & 7.35 & Amp. \\
\hline Short Circuit Current & $\mathrm{I}_{\mathrm{SC}}$ & 7.84 & Amp. \\
\hline No. of modules connected in series & & 2 & \\
\hline Load & & 1600 & $\Omega$ \\
\hline
\end{tabular}

Table 1: System Parameter 


\subsection{Block Diagram of System}

Fig.7 Show Block Diagram of PV system with MPPT and CPG mode control. Perturb and Observe algorithm is used for MPPT-CPG control of PV system. PV panel output voltage $\mathrm{V}_{\mathrm{pv}}$ and PV panel current $\mathrm{I}_{\mathrm{pv}}$ is sensed by the MPPT-CPG algorithm and accordingly it changes duty cycle of Boost converter such that it operates in either MPPT or CPG mode.

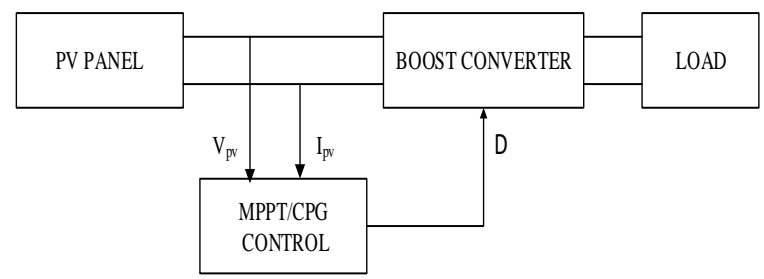

\subsection{Result:}

Figure 7: Simplified Diagram of PV System with MPPT-CPG mode

\subsubsection{For varying Irradiation Condition and Constant Temperature}

The Irradiation level is initially $500 \mathrm{~W} / \mathrm{m}^{2}$ at $\mathrm{t}=0$ and change in Irradiation level is made at $\mathrm{t}=0.15$ to $1000 \mathrm{~W} / \mathrm{m}^{2}$. Again it goes to $500 \mathrm{~W} / \mathrm{m}^{2}$ at $\mathrm{t}=0.25$. Temperature is maintained constant at $25^{\circ} \mathrm{C}$.

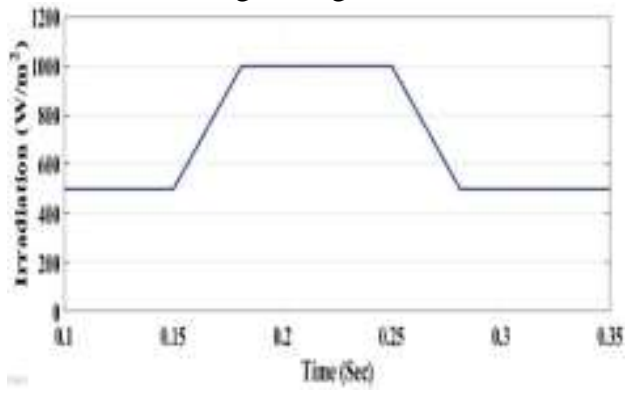

(a)

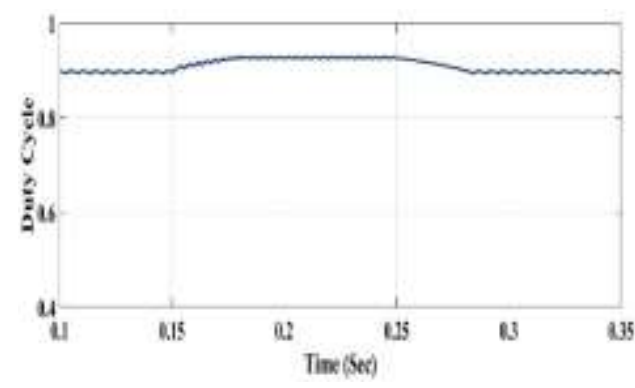

(b)

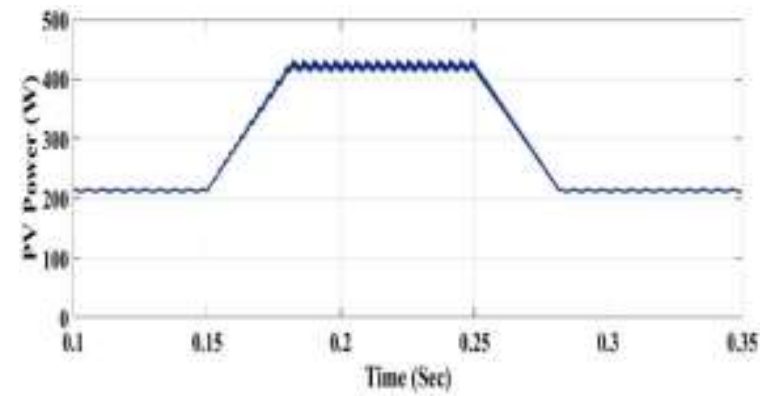

(c)

Figure 8: Result for changing Irradiation level from 500 to 1000 to again $500 \mathrm{~W} / \mathrm{m}^{2}$. (a) Irradiation v/s Time, (b) Duty Cycle v/s Time, (c) PV Power v/s Time

\subsubsection{For varying Temperature and Constant Irradiation level}

The Temperature is initially set to $25^{\circ} \mathrm{C}$ at $\mathrm{t}=0$, then change in it made at $\mathrm{t}=0.15$ to $45^{\circ} \mathrm{C}$ and again it goes to $25^{\circ} \mathrm{C}$ at $\mathrm{t}=0.25$. Irradiation level is maintained constant at $1000 \mathrm{~W} / \mathrm{m}^{2}$. 


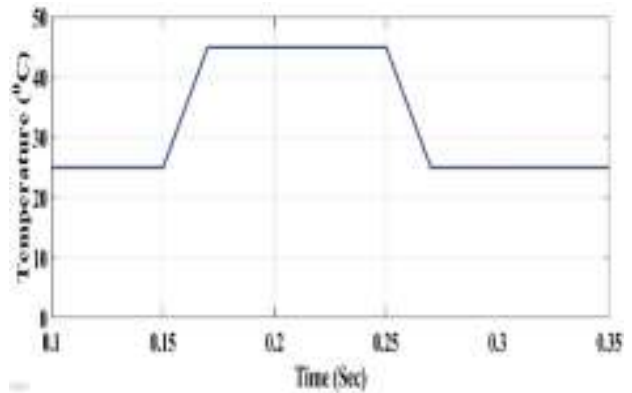

(a)

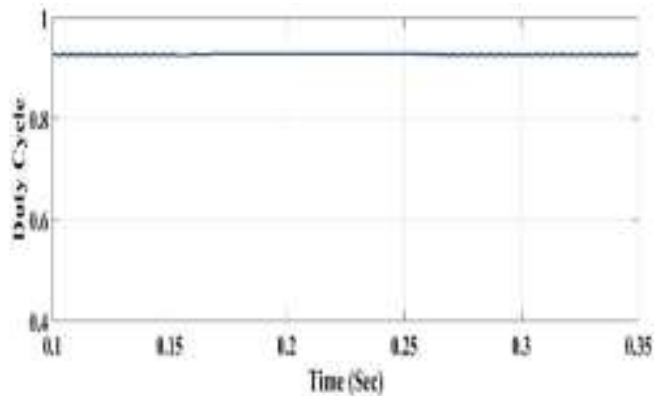

(b)

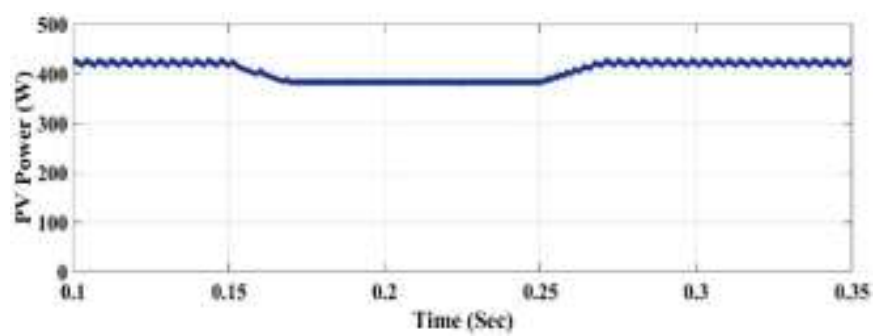

(c)

Figure 9: Result for changing Temperature from 25 to 45 to again $25{ }^{\circ} \mathrm{C}$. (a) Irradiation level v/s Time, (b) Duty Cycle v/s Time, (c) PV Power v/s Time

\begin{tabular}{|c|c|c|}
\hline \multicolumn{3}{|c|}{ For Varying Irradiation Condition } \\
\hline \multicolumn{2}{|c|}{ Load $=1600 \Omega$} & Temperature $=25^{\circ} \mathrm{C}$ \\
\hline $\begin{array}{c}\text { Irradiation } \\
\text { level }\end{array}$ & Duty Cycle & $\begin{array}{c}\text { Maximum Power } \\
\text { Transfer }\end{array}$ \\
\hline 1000 & 0.93 & 425.8 \\
\hline 800 & 0.921 & 343.5 \\
\hline 700 & 0.9156 & 301.6 \\
\hline 500 & 0.9 & 215.9 \\
\hline 300 & 0.872 & 128.8 \\
\hline 200 & 0.844 & 84.92 \\
\hline
\end{tabular}

Table 2: Duty Cycle to obtain Maximum Power Transfer for Varying Irradiation Condition

\begin{tabular}{|c|c|c|}
\hline \multicolumn{3}{|c|}{ For varying Temperature } \\
\hline Load=1600 $\Omega$ & Irradiation level $=1000 \mathrm{~W} / \mathrm{m}^{2}$ \\
\hline Temperature & Duty Cycle & $\begin{array}{c}\text { Maximum } \\
\text { Power Transfer }\end{array}$ \\
\hline 20 & 0.929 & 434.4 \\
\hline 25 & 0.93 & 425.8 \\
\hline 30 & 0.931 & 417.1 \\
\hline 35 & 0.932 & 408.4 \\
\hline 40 & 0.9325 & 399.7 \\
\hline
\end{tabular}

Table 3: Duty Cycle to obtain Maximum Power Transfer for Varying Temperature

\subsubsection{Constant Power Generation Control}

The Irradiation level is initially $500 \mathrm{~W} / \mathrm{m}^{2}$ at $\mathrm{t}=0$ and change in Irradiation level is made at $\mathrm{t}=0.15$ to $1000 \mathrm{~W} / \mathrm{m}^{2}$. Again it goes to $500 \mathrm{~W} / \mathrm{m}^{2}$ at $\mathrm{t}=0.25$. Temperature is maintained constant at $25^{\circ} \mathrm{C}$. The maximum feed in power is limited $\mathrm{P}_{\text {limit }}$ to $341 \mathrm{~W}$. 


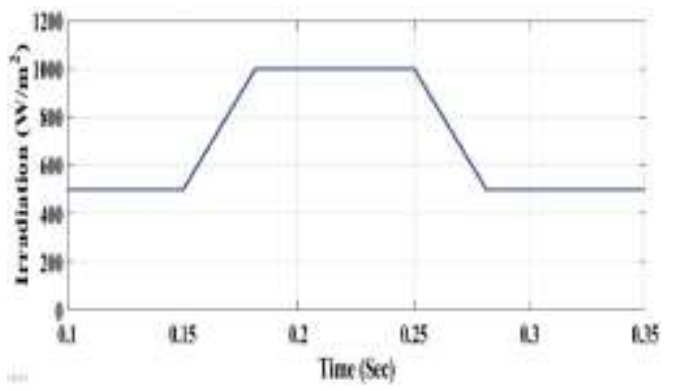

(a)

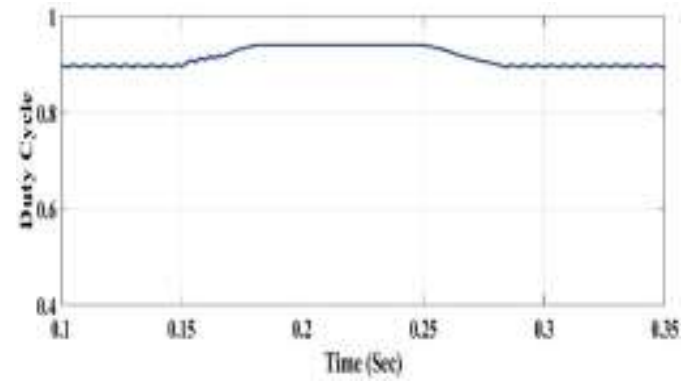

(b)

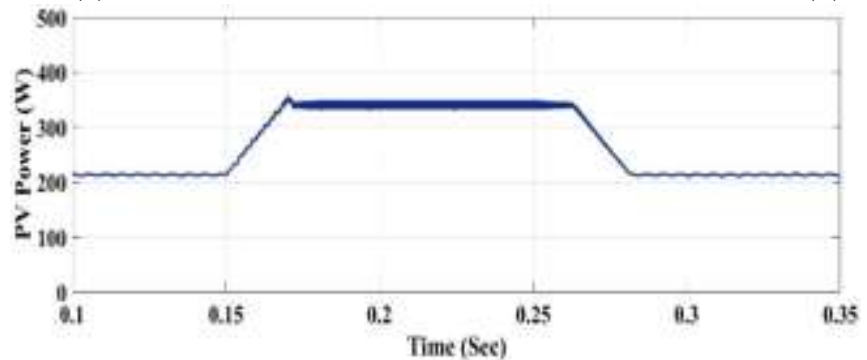

(c)

Figure 10: Result for CPG control (a) Irradiation level v/s Time, (b) Duty Cycle v/s Time, (c) PV Power v/s Time

\section{Conclusion}

The coordinated control of Maximum Power Point Tracking (MPPT) and Constant Power Generation (CPG) is implemented with Perturb \& Observe (P\&O) algorithm. The variation in irradiation level is considered from $200 \mathrm{~W} / \mathrm{m}^{2}$ to $1000 \mathrm{~W} / \mathrm{m}^{2}$. The variation in duty cycle of boost converter has transferred the maximum power from $84.92 \mathrm{~W}$ to $425.8 \mathrm{~W}$. Similarly algorithm is also tested for temperature variation. The implementation of CPG control has put the PV penetration limit up to $341 \mathrm{~W}$. The dynamic response of boost converter for close loop duty cycle control has effectively addressed the high PV penetration issue with active power control in MPPT and CPG mode.

\section{References}

[1] M. A. G. De Brito, L. Galotto, L. P. Sampaio, G. d. A. e Melo, and C. A. Canesin, "Evaluation of the main MPPT techniques for photovoltaic applications," IEEE transactions on industrial electronics, vol. 60, pp. 1156-1167, 2013.

[2] R. Abdul-Kalaam, S. Muyeen, and A. Al-Durra, "Review of Maximum Power Point Tracking Techniques for Photovoltaic System," Global Journal of Control Engineering and Technology, vol. 2, pp. 8-18, 2016

[3] Y. Yang, F. Blaabjerg, H. Wang, and M. G. Simoes, "Power control flexibilities for gridconnected multi-functional photovoltaic inverters," IET Renewable Power Generation, vol. 10, pp. 504-513, 2016.

[4] Y. Yang, F. Blaabjerg, and H. Wang, "Constant power generation of photovoltaic systems considering the distributed grid capacity," in 2014 IEEE Applied Power Electronics Conference and Exposition-APEC 2014, 2014, pp. 379-385.

[5] A. Sangwongwanich, Y. Yang, F. Blaabjerg, and H. Wang, "Benchmarking of constant power generation strategies for single-phase grid-connected Photovoltaic systems," in 2016 IEEE Applied Power Electronics Conference and Exposition (APEC), 2016, pp. 370-377. 
[6] Y. Yang, Advanced control strategies to enable a more wide-scale adoption of single-phase photovoltaic systems: Videnbasen for Aalborg UniversitetVBN, Aalborg UniversitetAalborg University, Det Teknisk-Naturvidenskabelige FakultetThe Faculty of Engineering and Science, 2014.

[7] A. Sangwongwanich, Y. Yang, and F. Blaabjerg, "High-performance constant power generation in grid-connected PV systems," IEEE Transactions on Power Electronics, vol. 31, pp. 1822-1825, 2016.

[8] A. Sangwongwanich, Y. Yang, and F. Blaabjerg, "Sensorless reserved power control strategy for two-stage grid-connected Photovoltaic systems," in Power Electronics for Distributed Generation Systems (PEDG), 2016 IEEE 7th International Symposium on, 2016, pp. 1-8.

[9] Y. Yang, H. Wang, and F. Blaabjerg, "Improved reliability of single-phase PV inverters by limiting the maximum feed-in power," in 2014 IEEE Energy Conversion Congress and Exposition (ECCE), 2014, pp. 128-135

[10] Y. Yang, E. Koutroulis, A. Sangwongwanich, and F. Blaabjerg, "Minimizing the levelized cost of energy in single-phase photovoltaic systems with an absolute active power control," in 2015 IEEE Energy Conversion Congress and Exposition (ECCE), 2015, pp. 28-34. 